\title{
A 29-year-old male with a long history of atraumatic wrist pain
}

\author{
William Tilden $^{1} \cdot$ Daniel Lindsay $^{1} \cdot$ Emmanouil Astrinakis $^{2} \cdot$ Maxim Horwitz $^{2} \cdot$ Asif Saifuddin $^{1}$
}

Received: 27 November 2020 / Revised: 9 February 2021 / Accepted: 14 February 2021 / Published online: 12 March 2021

(C) ISS 2021

\section{Discussion}

Figure 1 shows gross osteopenia of the distal radius, ulna, carpus and metacarpal bases with a lytic lesion in the ulnarside of the capitate. Figure 2a demonstrates a well-defined lesion with a sclerotic margin in the capitate which exhibits central signal void (Fig. 2a and c), correlating with dense calcification on CT (Fig. 3). The lesion contains multiple fluid-fluid levels (Fig. 2b). There is marked inflammatory change with oedema-like signal in the remaining capitate and adjacent hamate, as well as soft tissue oedema and synovitis around the carpus (Fig. 2). CT also demonstrates profound osteopenia of the whole carpus presumably related to chronic pain and disuse, although this can also be attributable to localised hyperaemia caused by osteoblastoma. The lesion was treated with curettage. Figure 4a shows a bone-forming tumour composed of anastomosing trabeculae of woven bone with osteoblastic rimming, scattered osteoclast-like giant cells and an intervening vascularised stroma. There is no significant cytological atypia and host bone permeation is not identified, confirming the benign nature of the lesion. Areas of aneurysmal bone cyst (ABC)-like change are also identified (cystic spaces with prominent osteoclast-like giant cells and foci of hemosiderin deposition) Fig. 4b (H\&E, $\times 20)$.

Osteoblastoma is a locally aggressive bone-forming tumour which is histologically similar to osteoid osteoma but

The case presentation can be found at doi: https://doi.org/10.1007/ s00256-021-03742-7

ANSWER: Osteoblastoma of the capitate with aneurysmal bone cyst-like change.

William Tilden

wtilden5@gmail.com

1 The Royal National Orthopaedic Hospital, Brockley Hill, Stanmore HA7 4LP, UK

2 Chelsea and Westminster Hospital, London, UK has potential for continued growth and usually measures $>2 \mathrm{~cm}$ in dimension. The spine, particularly the neural arch, is the commonest location affecting over one-third of cases, but the pelvis, femur and tibia are also relatively common sites. However, any skeletal location can be affected [1].

Primary bone tumours of the carpus account for $\sim 0.16 \%$ of osseous neoplasms, the commonest bones affected being the scaphoid and capitate and the commonest lesion osteoid osteoma [2]. Osteoblastomas of the capitate are exceedingly rare, with only 2 previously described cases $[3,4]$. Lesions in the hand and wrist are more likely to favour the metacarpals or the scaphoid [3]. Radiographic features are similar to those seen in long tubular bones, with lesions usually being round or oval, well-marginated, expansile and predominantly lytic with areas of ossified matrix. MRI will demonstrate the characteristic inflammatory component which normally manifests as osteitis, soft tissue oedema and possibly synovitis if a joint is involved [5].

$\mathrm{ABC}$-like changes most frequently accompany giant cell tumour, chondroblastoma and fibrous dysplasia but are also well-documented in association with osteoblastoma [6]. Telangiectatic osteosarcoma is also a well-recognised cause [7]. The differential diagnosis would include primary $\mathrm{ABC}$, as well as $\mathrm{ABC}$-like change within an osteoid osteoma (although to our knowledge this has not been reported), chondroblastoma or GCT. Such a profound inflammatory response would be unlikely in all of these except for osteoid osteoma, which is smaller and associated with more reactive sclerosis than the current case. In fact, reported cases of capitate osteoid osteoma have initially been misdiagnosed as avascular necrosis due to the degree of surrounding sclerosis [8-10]. Telangiectatic osteosarcoma could also be considered given the aggressive appearances and fluid-fluid levels, but the well-defined margins and lack of extra-osseous soft tissue mass makes this less likely. Also, we are unaware of any cases having been reported in the carpus. 
Fig. 2 a Coronal and $\mathbf{b}$ sagittal STIR images of the wrist demonstrate a well-defined, expansile lesion with a sclerotic margin (white arrows) in the capitate, which has provoked a prominent oedematous marrow reaction in the capitate and hamate (arrowheads). The lesion contains areas of low SI due to calcified matrix and fluid SI areas due to ABC-like change (thin blue arrow, b)
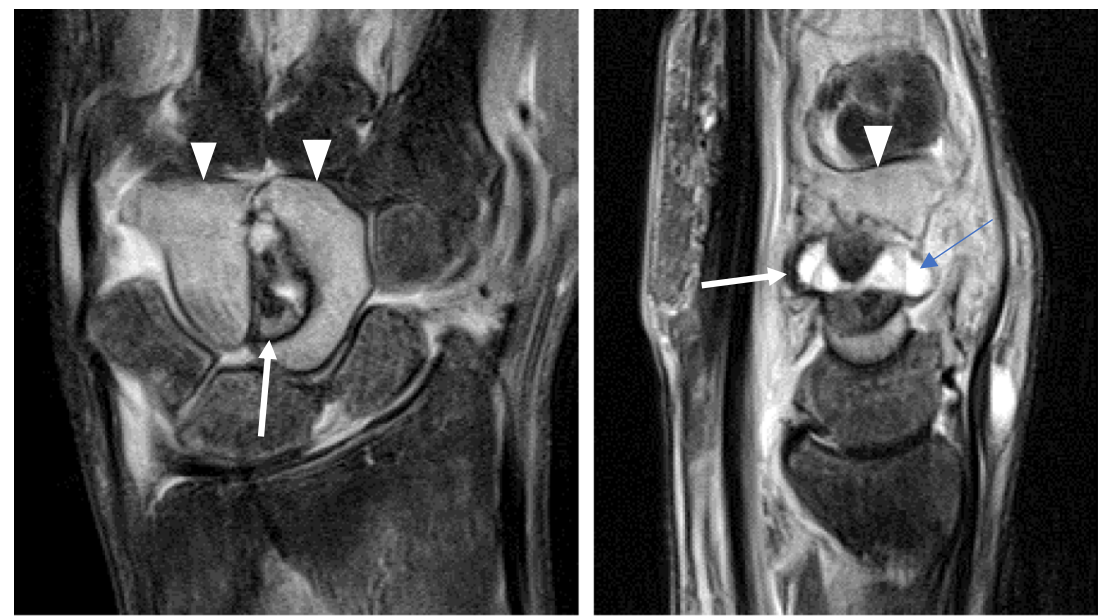

b

\section{References}

1. WHO classification of tumours editorial board. Soft tissue and bone tumours. Lyon (France). International Agency for Research on Cancer; 2020. WHO classification of tumours series. 5th Ed.; Volume 3. https://publications.iarc.fr/588.

2. Murray PM, Berger RA, Inwards CY. Primary neoplasms of the carpal bones. J Hand Surg. 1999;24:1008-13.

3. Afshar A. Osteoblastoma of the capitate bone. J Hand Microsurg. 2016;04:34-8.

4. Kaptan Ç, Atmaca H. Osteoblastoma of the Os Capitatum. Case Rep Orthop [Internet]. 2014 [cited 2020 Nov 20];2014. Available from: https://www.ncbi.nlm.nih.gov/pmc/articles/PMC4101925/.

5. Resnick D, Kyriakos M, Greenway G. Tumours and tumor-like lesions of bone: imaging and pathology of specific lesions. Diagn Bone Jt Disord. 4th ed. Philadelphia: W. B. Saunders Company; 2002. p. $3763-4128$.
6. Gutierrez LB, Link TM, Horvai AE, Joseph GB, O'Donnell RJ, Motamedi D. Secondary aneurysmal bone cysts and associated primary lesions: imaging features of 49 cases. Clin Imaging. 2020;62: 23-32.

7. Zishan US, Pressney I, Khoo M, Saifuddin A. The differentiation between aneurysmal bone cyst and telangiectatic osteosarcoma: a clinical, radiographic and MRI study. Skeletal Radiol. 2020;49: 1375-86.

8. Schindler A, Hodler J, Michel BA, Bruehlmann P. Osteoid osteoma of the capitate. Arthritis Rheum. 2002;46:2808-10.

9. Mehdizade A, Danon M, Ellis S, Wolfe S, Adler RS. Use of ultrasonographic guidance for needle localization of osteoid osteoma of the capitate. HSS J. 2006;2:176-80.

10. Kreitner K-F, Löw R, Mayer A. Unusual manifestation of an osteoid osteoma of the capitate. Eur Radiol. 1999;9:1098-100.

Publisher's note Springer Nature remains neutral with regard to jurisdictional claims in published maps and institutional affiliations. 